\title{
Bottom Anti-Reflective Coatings for DUV Lithography
}

\author{
Wen-Bing Kang", Hatsuyuki Tanaka", Ken Kimurab, Munirathna Padmanaban", \\ Satoru Funato", Yoshiaki Kinoshita", Takanori Kudo", Yuko Nozaki", and Georg Pawlowski" \\ a) Lithography Team, Corporate Research \& Technology, Hoechst Japan Limited \\ 1-3-2, Minamidai, Kawagoe-Shi, Saitama, Japan \\ b) IC Photoresist Team, Business Unit Electronic Materials, Hoechst Japan Limited \\ 3810, Chihama, Daito-Cho Ogasa-Gun, Shizuoka, Japan
}

\begin{abstract}
Bottom anti-reflective coatings (BARC) provide a production proven solution to improve linearity, depth-of-focus, $\mathrm{CD}$ control and process latitudes of photoresists. A series of BARCs compatible with chemically amplified deep ultra-violet (DUV) photoresists exhibiting different $k$ values ranging from 0.1 to 0.6 at the DUV wavelength $(248 \mathrm{~nm})$ has been developed. The relationship between the $k$ values and the etch rates of the BARC polymers with different dye concentrations in the polymer has been investigated. As a result, BARCs with targeted $\mathrm{k}$ values and etch rates can be provided. Formulation aspects of the BARC materials including edge bead remover (EBR) compatibility and evaluation results of these BARCs with different DUV resists are also discussed.
\end{abstract}

Keywords: DUV, ARC, BARC, Bottom Anti-Reflective Coating, Anti-reflection.

\section{Introduction}

Mass production of IC devices using deep ultra-violet (DUV) lithography with critical dimensions (CD) of $0.25 \mu \mathrm{m}$ is scheduled to ramp up within this year by the most advanced chip manufacturers. Research and development work on higher integrated circuits with $0.18 \mu \mathrm{m}$ design rules is underway and suitable lithographic strategies are under trial evaluation.

Reflection of radiation from the substrate into the photoresist layer is a general problem of standard photoresist exposure processes, which is further aggravated when the limits of optical lithography are attained. Reflective topographic substrates will cause changes of the swing ratio of the resist and generate linewidth variations, standing waves and reflective notching in the resist profiles. Application of bottom anti-reflective coatings (BARC) have been found to be an effective tool to reduce, or eliminate substrate reflection. This is why BARCs are widely used in the advanced processing of high resolution type $\mathrm{i}$-line resists. As an example, AZ ${ }^{\circledR}$ BARLi (AZ Photoresist 
Products, Hoechst), an organic BARC specially designed for $\mathrm{i}$-line lithography, has found application in numerous production processes. ${ }^{\text {) }}$

Chemically amplified deep ultra-violet (DUV; 248 $\mathrm{nm}$ ) and very deep ultraviolet (VDUV; $193 \mathrm{~nm}$ ) sensitive photoresists are usually very transparent at the exposure wavelength. As both, the photoresist and substrate reflectivity increase at these wavelengths reflection control becomes a more important issue for DUV and VDUV lithography processes.

The swing ratio $\mathrm{S}$ - a measure for film thickness induced $\mathrm{CD}$ changes of photoresists - has been described by Brunner using the simple equation (1):

$$
S=4 \sqrt{R_{s} R_{r}} e^{-\alpha D}
$$

where $\alpha$ is the resist absorption, D is the resist film thickness, $R_{r}$ is the reflectivity at the resist/air, or resist/top antireflective coating (TARC) interface, and $\mathbf{R}_{\mathbf{s}}$ is the reflectivity at the substrate/resist interface. $^{\text {(a) }}$

In order to reduce the swing ratio of a resist, several methods have been proposed:

1) addition of dyes to increase absorption $\alpha$ of the resist (decrease of $\mathrm{e}^{-\alpha \mathrm{D}}$ term),

2) use of top antireflective coatings (TARC) to reduce the reflectivity of the resist top interface (decrease of $\mathbf{R}_{\mathbf{r}}$ ),
3) use of bottom antireflective coatings to reduce the reflectivity of the resist bottom interface (decrease of $R_{s}$ ),

4) use of some other optical measures for resist exposure.

The incorporation of dyes into the resist formulation with absorption at the exposure wavelength has some limitations such as loss of photosensitivity and resolution. The application of TARCs can reduce the swing ratio but does not eliminate reflective notching caused by topographic substrates. Both, inorganic and organic bottom antireflective coatings have proven to be useful for $\mathrm{CD}$ control and standing wave reduction and are now considered as mandatory tools for the reduction of reflection in DUV/VDUV processes.

As almost all of currently available DUV resists are based on chemical amplification (CA) mechanisms, requirements on the DUV BARC materials are even more critical than those for i-line BARCs. As an example, small amounts of alkaline contaminants will strongly affect photoresist performance as the acid produced in CA resists will be neutralized at the substrate/resist interface resulting in severe footing. In contrast, acidic functionalities in the BARC material may cause undercut profiles and resist collapse.

Table 1: List of commercially available UV BARCs

\begin{tabular}{|c|c|c|l|l|l|}
\hline Name & $\mathrm{n}$ & $\mathrm{k}$ & \multicolumn{1}{|c|}{ Solvents } & Company & \multicolumn{1}{|c|}{ Remarks } \\
\hline $\begin{array}{c}\mathrm{CD}-9 / \\
\mathrm{CD}-11^{3)}\end{array}$ & 1.79 & 0.23 & $\begin{array}{l}\text { Cyclohexanone \& } \\
\text { g-butyrolactone }\end{array}$ & $\begin{array}{l}\text { Brewer } \\
\text { Science }\end{array}$ & $\begin{array}{l}\text { Limited compatibility to resists. } \\
\text { Low etch rate. }\end{array}$ \\
\hline $\mathrm{DUV}-18^{3)}$ & 1.50 & 0.51 & Resist solvents & Brewer & Resist dependent \\
\hline $\mathrm{AR}^{4} \mathbf{1}^{4}$ & 1.50 & 0.51 & Resist solvents & Shipley & Same as DUV-18 \\
\hline $\mathrm{AZ}^{\circledR} \mathrm{BARLi}^{\circledR}$ & 1.65 & 0.23 & Cyclohexanone & Hoechst & $\begin{array}{l}\text { Resist dependent, high etch rate } \\
\text { Good step coverage }\end{array}$ \\
\hline
\end{tabular}


Currently, there are several organic DUV BARCs commercially available as listed in Table 1 . Organic BARCs are usually deposited on the substrate by spinning from solutions. The remarks included in this table are quotations of publications of the respective product supplier. The comments indicate that many of the BARC properties have to be optimized in view of the selected resist and performance changes may be seen upon resist variation. This may be due to the high sensitivity of CA type of DUV resist to substrates. Therefore, development of BARC materials with compatibility to DUV resists of variable chemistries and components is required.

In this paper, the synthesis of new DUV BARCs based on the experience obtained from $A Z^{\oplus} B A R L i$ is described. Some evaluation results of these BARCs with DUV resists are also discussed.

\section{Design of DUV BARCs}

The following material characteristics should be taken into account for the design of BARCs for DUV resists.

1) High absorption (allows thin film use).

2) High etch rate (facilitates smooth pattern transfer).

3) Uniform film thickness (conformality) over topography (improves reflection and etch control).

4) No particles nor film defects (pinholes).

5) No photoresist intermixing.

6) No photoresist footing or undercut.

7) Full compatibility with standard photoresist/ lithography processes.

The reflectivity from the BARC layer into the photoresist layer has been calculated with PROLITH/2 (V4.05 by Finle Technologies) for the combination of a photoresist with a refractive index (real part) $\mathrm{n}=1.76$ and an absorption $\alpha=0.28 \mu \mathrm{m}^{-1}$ and a BARC material with $n=1.441$ and different $k$ values (imaginary part of the refractive index) at $\mathbf{2 4 8}$ $\mathrm{nm}$ on a silicon substrate. According to equation (2), the $k$ value of a material is proportional to the absorption $\alpha$ :

$$
k=\alpha \lambda / 4 \pi
$$

The results of this simulation are shown in Figure 1. It is evident from inspection of the diagram that the first reflection minimum shifts to smaller BARC film thickness with the increase of the $\mathrm{k}$ value. Initially, the reflectivity at the first minimum also decreases with increasing $\mathrm{k}$ value but increases after passing an optimum. This is due to the fact that highly absorbing BARCs may act as mirrors. Due to the necessity to delineate smaller resist features, IC producers tend to apply thinner resist films. As the possibilities to increase BARC/resist etch selectivity are limited, thinner BARC layers are preferred for an effective etch process and a sufficiently high $k$ value of the BARC may compensate for decreasing absorption due to thinner BARC film thickness.

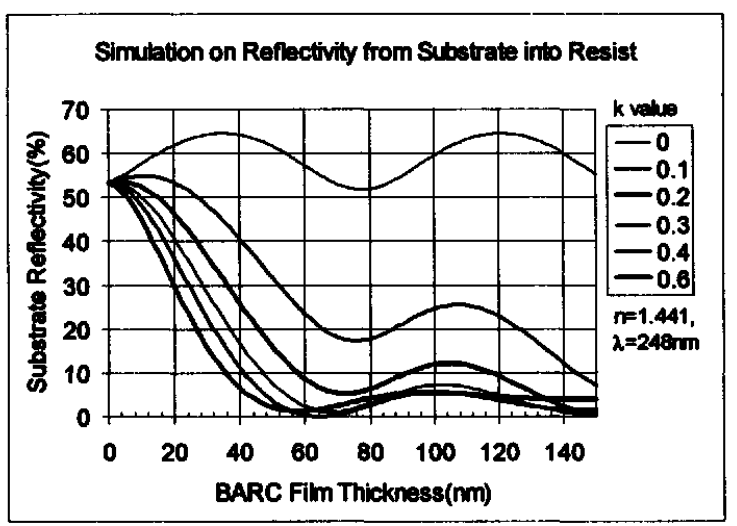

Figure 1: Simulation of reflectivity from BARC into resist

The simulation of the relative swing ratio of the resist to $\mathrm{Si}$ in Figure 2 indicates that there is an optimum $\mathrm{k}$ value $(k=0.42-0.48)$ for the lowest swing reduction 
for a resist. The optimum conditions of a BARC with different resists can be simulated and this performs as a tool for the matching of BARC and resists.

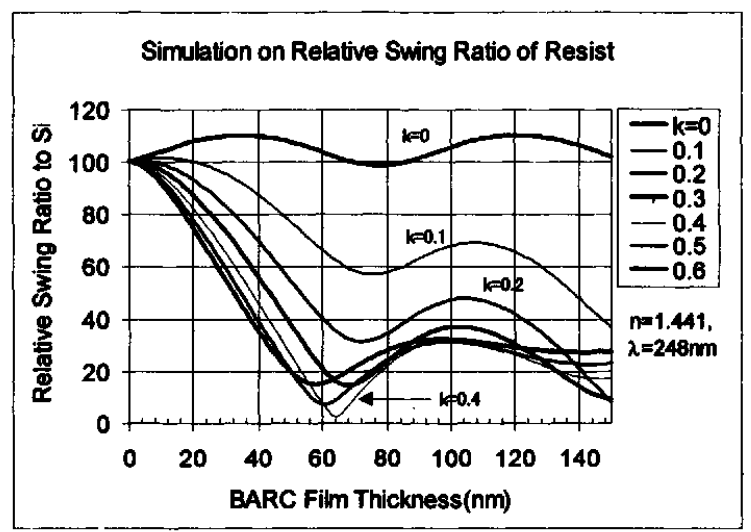

Figure 2: Relative swing ratio of resist to $\mathrm{Si}$

Organic BARC materials can be synthesized by either physically mixing a low molecular weight dye material into an inert polymer binder, or chemically attaching dyes directly to a reactive polymer backbone. Free dye sublimation upon baking of the BARC layer and diffusion of dyes into the resist layer from dye mixed BARCs during photoresist processing have been observed causing severe problems in resist performance generating footing or undercut in the resist profile, or high defect rates. In order to avoid these BARC related problems, we have synthesized and investigated polymer materials with the dye molecules directly attached to the polymer backbone by chemical links. This has been achieved by either polymer analogue reaction of an appropriate functional dye with a reactive polymer, or the polymerization of monomeric dyes. The BARC formulations with these DUV polymers do not contain free dyes and were found to be capable to match with various DUV resists.

These investigations lead to several DUV BARC materials optimized for DUV lithography which have high absorption, excellent conformality and appropriate etch rates. Some of these new BARCs exhibit high solubility in resist solvents and show full EBR compatibility. Through selection and fine tuning of the comonomer ratio these materials can be optimized to match with different photoresist systems.

\section{New BARC Materials}

The UV spectra of a large number of aromatic and aliphatic dyes were recorded and checked for effective absorption at $248 \mathrm{~nm}$. Only aromatic dyes with fused rings, such as naphthalene or anthracene derivatives, were found to have sufficient absorption in the DUV range. Dyes with extinction coefficients $\varepsilon$ higher than 30,000 to 100,000 at $248 \mathrm{~nm}$ were selected for BARC polymer synthesis.

\subsection{DUV BARC KrF Series}

Materials of the DUV BARC $\mathrm{KrF}$ series were obtained by the polymer analogue reaction of DUV absorbing dyes with a reactive polymer. The $k$ values of the dye attached polymer can be adjusted by change of the dye concentration in the range of 0.1 to 0.5 at $248 \mathrm{~nm}$.

The BARC polymers thus isolated have good solubility in ketone, or amide type solvents, such as cyclohexanone and dimethylacetamide. In contrast, the polymers are almost insoluble in most of the common resist solvents. Contact of the BARC film baked at various temperatures with resist solvents such as ethyl lactate (EL), propylene glycol methyl ether acetate (PGMEA), or methyl amyl ketone (MAK) showed in general less than $1 \%$ film thickness change (cf. Table 2.). Therefore, no intermixing of the BARC layer with the resist during the lithographic process is anticipated and this has 
been comfirmed.

Table 2: Thickness change of BARC film upon contact with resist solvents

\begin{tabular}{|l|l|l|l|}
\hline Solvents & $180^{\circ} \mathrm{C}$ & $200^{\circ} \mathrm{C}$ & $220^{\circ} \mathrm{C}$ \\
\hline EL & $4 \AA$ & $-6 \AA$ & $4 \AA$ \\
\hline PGMEA & $10 \AA$ & $6 \AA$ & $7 \AA$ \\
\hline MAK & $-2 \AA$ & $-4 \AA$ & $3 \AA$ \\
\hline
\end{tabular}

Contact of solvents to the BARC films was done at room temperature and film was spin dried for $60 \mathrm{sec}$.

A selected DUV BARC sample, $\mathrm{KrF}-2$, with $\mathrm{n}=$ 1.551 and $\mathrm{k}=0.42$ at $248 \mathrm{~nm}$ has been investigated in more detail. Figure 3 shows the simulation results of the relative swing ratio with the DUV positive resist $A Z^{\circledast}$ DX $1100 \mathrm{P}$. The first optimum film thickness is in the range of about $55 \mathrm{~nm}$.

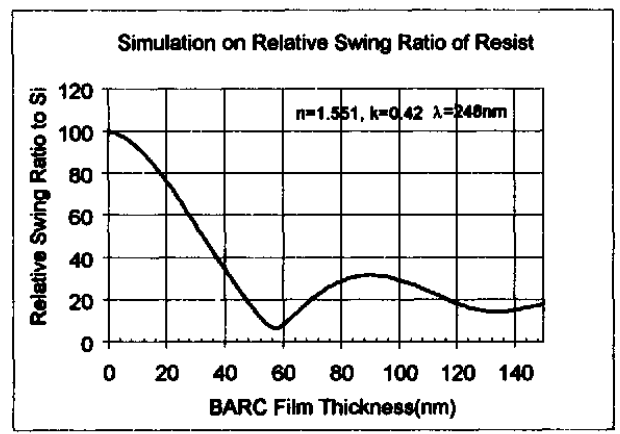

Figure 3: Relative swing ratio of AZ DX1100P to Si

Lithographic performance tests using two chemically amplified positive DUV resists of the acetal type showed that KrF-2 matches well with such low activation energy systems. Figures 4 and 5 show cross sectional SEM pictures of resist profiles of $A Z^{\circledR}$ DX $1100 \mathrm{P}$ and an experimental positive DUV resist B with $\mathrm{KrF}-2$ coated on $\mathrm{Si}$ at the BARC optimum thickness of $55 \mathrm{~nm}$. The applied processing conditions for BARC and resist materials are summarized in Table 3.

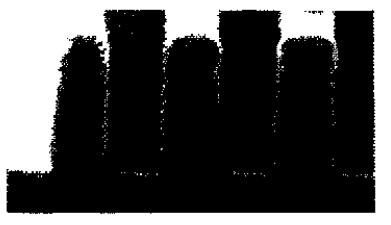

$0.30 \mu \mathrm{m}$

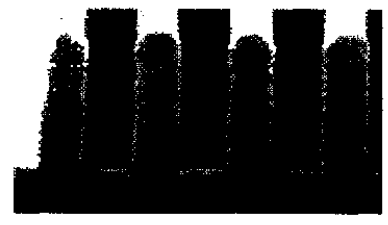

$0.25 \mu \mathrm{m}$
Figure 4: $\mathrm{KrF}-2$ with DUV resist $A Z^{\circledR} \mathrm{DX} 1100 \mathrm{P}$

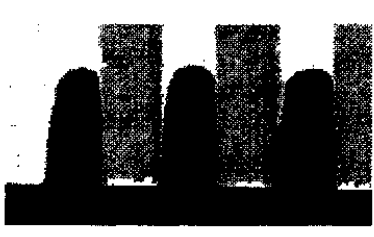

$0.30 \mu \mathrm{m}$

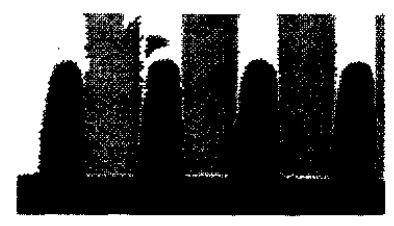

$0.25 \mu \mathrm{m}$
Figure 5: KrF-2 with experimental DUV resist B

Table 3: BARC and resist process conditions

\begin{tabular}{|c|c|}
\hline BARC & FT: $55 \mathrm{~nm}$, baked at $220^{\circ} \mathrm{C}$ for $60 \mathrm{sec}$. \\
\hline DX1100P & $\begin{array}{l}\text { FT: } 0.75 \mu \mathrm{m}, \mathrm{PB}: 110^{\circ} \mathrm{C} / 60 \mathrm{sec}, \\
\text { PEB: } 70^{\circ} \mathrm{C} / 90 \mathrm{sec}, \\
\text { Nikon } \mathrm{EX} 10 \mathrm{~B}, \mathrm{NA}=0.55, \sigma=0.55 \text {, } \\
\text { Dose: } 48 \mathrm{~mJ} / \mathrm{cm}^{2}, \\
\text { Developer: } \mathrm{AZ} 300 \mathrm{MIF}, 60 \mathrm{sec} \text {, } \\
\text { puddle. }\end{array}$ \\
\hline Resist B & $\begin{array}{l}\text { FT: } 0.75 \mu \mathrm{m}, \mathrm{PB}: 110^{\circ} \mathrm{C} / 60 \mathrm{sec}, \\
\text { PEB: } 105^{\circ} \mathrm{C} / 90 \mathrm{sec}, \\
\text { Nikon } \mathrm{EX} 10 \mathrm{~B}, \mathrm{NA}=0.55, \sigma=0.55 \text {, } \\
\text { Dose: } 50 \mathrm{~mJ} / \mathrm{cm}^{2} \text {, } \\
\begin{array}{l}\text { Developer: } \mathrm{AZ} \quad 300 \mathrm{MIF}, 60 \mathrm{sec} \text {, } \\
\text { puddle. }\end{array}\end{array}$ \\
\hline
\end{tabular}

Etch rate and coating conformality of BARCs are very important parameters. Etch tests of KrF-2 baked at several temperatures were done and compared with $\mathrm{AZ}^{\circledR}$ BARLi and $\mathrm{AZ}{ }^{\circledR}$ DX $1100 \mathrm{P}$ as listed in Table 4. As indicated, $\mathrm{KrF}-2$ has a slightly higher etch rate than the photoresist. KrF-2 shows excellent conformality over topography. Therefore, the BARC film thickness variations over such substrate are negligible resulting in better control of the etch process. 
Table 4: Etch selectivity of $\mathrm{KrF}-2$

\begin{tabular}{|l|l|l|l|l|}
\hline Baked Temp. $\left({ }^{\circ} \mathrm{C}\right)$ & 170 & 180 & 190 & 200 \\
\hline To AZ ${ }^{\circledR}$ BARLi & 0.95 & 0.89 & 0.91 & 0.87 \\
\hline To AZ DX 1100P & 1.1 & 1.08 & 1.09 & 1.08 \\
\hline
\end{tabular}

Etch conditions: Equipment: RIE-10N (SAMCO Inc.), Flow Rate: $\mathrm{CHF}_{3} / \mathrm{O}_{2}=40 / 10 \mathrm{sccm}, \mathrm{RF}$ Power: $60 \mathrm{~W}$; Etch Time: $60 \mathrm{sec}$.

\subsection{EBR Compatible DUV BARCs}

Due to the insolubility of some BARCs in resist solvents, users encounter the deposition of solid materials from the mixture of waste solutions of BARC and resist. Although this can be avoided by using different lines to drain the BARC and edge bead removers, users prefer to have EBR compatible BARCs. However, standard BARCs formulated in resist solvents exhibit solubility and intermixing problems upon resist application. To avoid intermixing effects, hardening of the BARC films via the use of crosslinking agents is necessary. As a consequence, significantly more control on the BARC formulation and the stability is required than those BARC systems which are insoluble in resist solvent.

This work studied the solubilities of polymers synthesized from a dye monomer and various acrylate type monomers. As a result, polymer samples with $\mathrm{k}$ values at $248 \mathrm{~nm}$ as high as 0.6 could be obtained. Adjustment of the polymer absorption, etch rate, and formulation for BARC application have been done as described below.

\subsubsection{Adjustment of Polymer Absorption and Etch Rate}

By changing the monomer ratio in the polymer synthesis polymer samples with different $k$ values were obtained. Figure 6 shows the relationship of the $k$ value and etch selectivity versus the above mentioned $\mathrm{KrF}-2$ with the relative dye concentration in the BARC polymer.

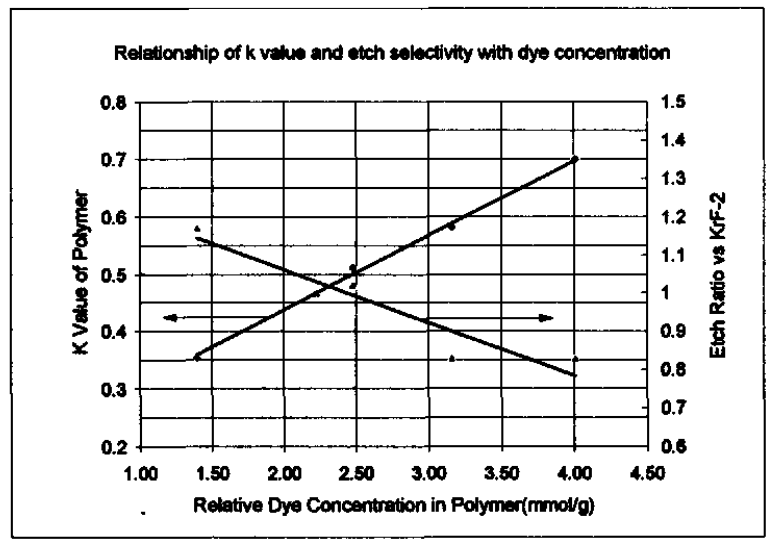

Figure 6: $\mathrm{k}$ value and etch selectivity dependency. (Etch rates were measured at the same conditions shown in Table 3.)

The experimental $k$ values of the polymers show very good linearity versus the dye concentration incorporated into the polymer system. It is therefore possible to synthesize polymers with a predicted $\mathrm{k}$ value. Etch selectivity of the polymer decreases as the dye concentration in the polymer increases. The etch ratio of this type of polymer is about $10-20 \%$ higher than that of $\mathrm{KrF}-2$ type polymers for the same $k$ value.

\subsubsection{Formulation of EBR Compatible BARCs}

As has been mentioned above, the base polymer exhibits high solubility in resist solvents such as PGMEA, or EL. To eliminate resist intermixing, it is essential to incorporate cross-linking functions capable to harden the BARC film during the bake step prior to resist coating. Similar to the dying strategy, the direct attachment of crosslinking functionalities into the BARC polymer offers advantages over physical polymer/crosslinker mixtures with respect to defect rates and conformality. With the modification of the polymer and the identification of some suitable additives, several 
BARC formulations were selected which are soluble in resist solvents and applicable to a large variety of chemically amplified DUV photoresists with different chemistries.

Intermixing of baked BARC films was investigated in more detail and one example is shown in Table 5. Test conditions applied were the same as those described for $\mathrm{KrF}-2$. The results show that baking of the BARC film at temperature higher than $200^{\circ} \mathrm{C}$ results in sufficient cross-linking in the BARC film to prevent the intermixing with the photoresist.

Table 5: Thickness change of BARC KrF-3 film

\begin{tabular}{|l|c|l|l|}
\hline Solvents & $180^{\circ} \mathrm{C}$ & $200^{\circ} \mathrm{C}$ & $220^{\circ} \mathrm{C}$ \\
\hline EL & $570 \AA$ & $70 \AA$ & $5 \AA$ \\
\hline PGMEA & $1050 \AA$ & $60 \AA$ & $-1 \AA$ \\
\hline MAK & $670 \AA$ & $35 \AA$ & $-1 \AA$ \\
\hline
\end{tabular}

\subsubsection{Lithographic Performance}

The lithographic performance of the new EBR compatible DUV BARC $\mathrm{KrF}-3$ was evaluated in combination with several chemically amplified positive DUV resists. The resist profiles of $A Z^{\circledR} \mathrm{DX}$ $1100 \mathrm{P}$ and the experimental resist $\mathrm{B}$ with the EBR compatible BARC KrF-3 are shown in Figures 7 and 8. The SEM pictures indicate that through fine tuning of the BARC composition good profiles without footing can be obtained. The cross-sectional SEM pictures were obtained at the same conditions as listed in Table 2.

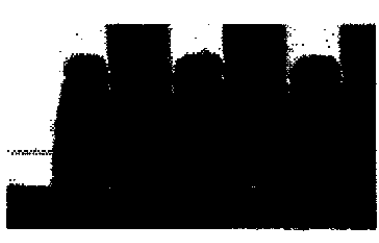

$0.30 \mu \mathrm{m}$

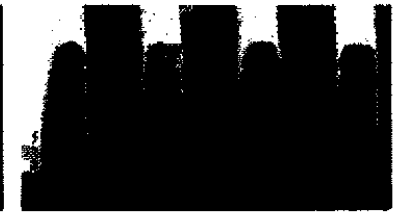

$0.25 \mu \mathrm{m}$
Figure 7: $\mathrm{AZ} \mathrm{Z}^{\circledR} \mathrm{DX} 1100 \mathrm{P}$ on $\mathrm{KrF}-3$

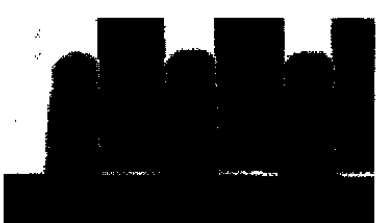

$0.30 \mu \mathrm{m}$

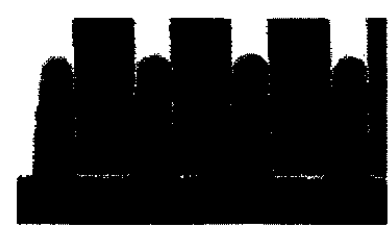

$0.25 \mu \mathrm{m}$
Figure 8: Resist $\mathrm{B}$ on $\mathrm{KrF}-3$

\section{Conclusions}

A variety of novel organic DUV BARCs has been developed. Control of the $k$ value and the etch rate of the BARC polymer is possible by optimizing the dye concentration and incorporation of suitable comonomers. These new BARCs show good etch selectivities against currently marketed DUV resists. EBR compatible BARCs with fine-tuned $k$ values are now available from Hoechst and these BARCs are fully compatible with chemically amplified DUV resists of different chemistries.

\section{Acknowledgments}

The authors would like to thank Dr. Ralph Dammel of Hoechst Celanese Corporation for stimulating discussions on the simulation of BARC materials. The support of DUV photoresist team members is also acknowledged.

\section{References}

1. For introductions on BARCs see:

a) T.A. Brunner, Proc., SPIE Vol. 1466, 297 (1991).

b) J. Fahey et al., Proc., SPIE Vol. 2195, 422 (1994).

c) R. R. Kunz, Proc., SPIE Vol. 2195, 447 (1994).

d) R. R. Dammel, Semiconductor Fabtech., 2, 215 (1995).

e) R. R. Dammel and R. A. Norwood, Proc., SPIE Vol. 2724, 754 (1996).

2. D. Guerrero and J. Lamb, SEMATECH DUV Workshop, October 1996.

3. E. K. Pavelchek et al., Proc., SPIE Vol. 2724, 692 (1996). 